\title{
Imaginary Dialogues in Mathematics Education
}

\author{
Annika M. Wille
}

Received: 12 October 2015 / Accepted: 21 October 2016 / Published online: 11 November 2016

(C) The Author(s) 2016. This article is available at SpringerLink with Open Access.

\begin{abstract}
An imaginary dialogue is a form of mathematical writing where a single student composes a written dialogue between two protagonists who discuss a mathematical task or question (Wille 2008). The aim of this article is to discuss from a theoretical perspective the potential and limitations of the use of imaginary dialogues in mathematics education in order to understand students' mathematical thinking processes. Grade 5 students' writing on fractions will serve to exemplify the theoretical line of argumentation.
\end{abstract}

Keywords Mathematical writing - Imaginary dialogues $\cdot$ Mathematical thinking processes $\cdot$ Reflection

Mathematics Education Subject Classification C30 - C50 · E40

\section{Erdachte Dialoge in der Mathematikdidaktik}

Zusammenfassung Ein erdachter Dialog ist eine Form des Schreibens im Mathematikunterricht, wobei eine Schülerin oder ein Schüler einen schriftlichen Dialog zwischen zwei Protagonisten verfasst, die sich über eine mathematische Aufgabe oder Frage unterhalten (Wille 2008). Ziel dieses Artikels ist es, Möglichkeiten und Grenzen des Einsatzes von erdachten Dialogen in der Mathematikdidaktik theoretisch zu diskutieren, um mathematische Denkprozesse zu verstehen. Schreibprodukte von Schülerinnen und Schülern der Jahrgangsstufe 5 über Brüche werden die theoretische Argumentation veranschaulichen.

\footnotetext{
A. M. Wille $(\triangle)$

Institute of Mathematics Education, University of Klagenfurt, Sterneckstraße 15, 9010 Klagenfurt, Austria

E-Mail: annika.wille@aau.at
} 
Schlüsselwörter Schreiben im Mathematikunterricht · Erdachte Dialoge ·

Mathematische Denkprozesse · Reflexion

\section{Introduction}

Over the last few years the author has conducted several studies that involve imaginary dialogues (Wille 2008, 2010, 2011, 2013; Wille and Boquet 2009), a form of mathematical writing where a single student composes a written dialogue between two protagonists who discuss a mathematical task or question (see Fig. 1 for one example of an imaginary dialogue of an 11 year old student written in German, for the English translation see Fig. 3).

The aim of this article is to discuss from a theoretical perspective the potential and limitations of the use of imaginary dialogues in mathematics education in order to understand students' mathematical thinking processes.

Of course, the idea of composing a written dialogue is not new. There are, for example, Plato's philosophical dialogues (428/427 BC to 348/347 BC). Moreover, a written dialogue between fictional students and a teacher about Euler's $V-E+F=2$ formula, can be found in Lakatos' Proofs and Refutations (1976). However, in the studies conducted by the author it is not a professional mathematician, philosopher, researcher, or teacher who is writing the dialogue, but in contrast one student him- or herself.

In order to understand a student's mathematical thinking process while he or she is writing an imaginary dialogue, it is necessary to clarify the relationship between the student's thinking and the imaginary dialogue. Moreover, working out the particular characteristics of imaginary dialogues can help to understand what kind of thinking processes may be expected.

In other words, the aim is to analyse this tool and to identify its potential and limitations in order to apprehend the mathematical thinking processes of students.
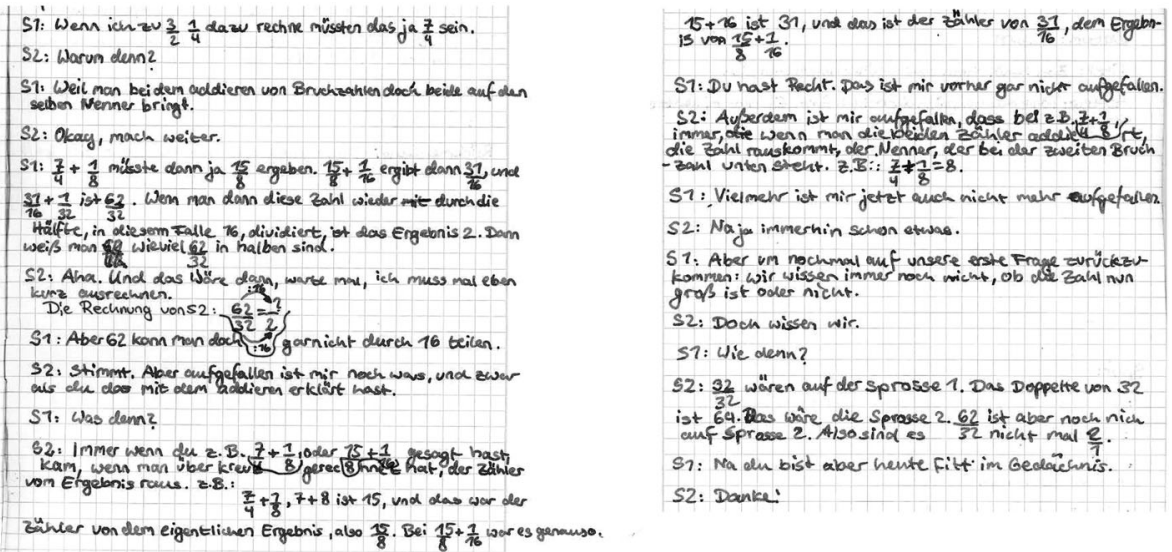

Fig. 1 The imaginary dialogue of the 11 year old student Emma written in German 
This article is structured as follows: First an example is given to illustrate what is meant by an imaginary dialogue (cf. Sect. 2). The learning environment of the imaginary dialogue task will only briefly be sketched, because the study itself is not the main focus of this paper. Instead it will serve to illustrate the findings from the theoretical discussion.

This is followed by two sections outlining theoretical approaches which underpin the aim of the paper, thus, to better understand and use imaginary dialogues: Firstly, imaginary dialogues will be regarded with the theoretical lens provided by the framework of commognition of Anna Sfard (2008) with the aim of clarifying the concepts thinking and learning and their relationship to the writing process (cf. Sect. 3). Secondly, theoretical considerations addressing the location of imaginary dialogues between spoken and written language (cf. Sect. 4.1) and further particular characteristics of imaginary dialogues (cf. Sect. 4.2) are outlined.

These considerations are then used (cf. Sect. 5) to address the article's main question - What is the potential and limitations of imaginary dialogues as a method to approach students' mathematical thinking processes? - followed by illustrating examples (cf. Sect. 6). In the last section consequences for the students' learning process, differences to other forms of mathematical writings, further research and open questions are discussed (cf. Sect. 7).

\section{A first example}

The following example is taken from a one year project in the school year 2008 and 2009, which was conducted by the author with fifth-grade students of a Grammar School (Gymnasium) in Bremen, Germany, in order to study amongst other topics their appreciation of fractions. The students got several tasks in the form of imagi-

Two students are talking with each other:

S1: $\quad$ Imagine I add 1 and $\frac{1}{2}$.

S2: $\quad$ Okay. That is $\frac{3}{2}$.

S1: $\quad$ Now add to the result $\frac{1}{4}$ and to the next result $\frac{1}{8}$ and to the next $\frac{1}{16}$, then $\frac{1}{32}$ and so forth.

S2: $\quad$ You mean something like this?

S2 is writing on a paper:

$1+\frac{1}{2}+\frac{1}{4}+\frac{1}{8}+\frac{1}{16}+\frac{1}{32}+\cdots$

S1: $\quad$ Exactly! That is getting quite big, or not?

S2 thinks...

S2: I am not so sure. I believe, it won't be that big.

S1: $\quad$ Maybe pictures will help us with it or we could calculate everything one after another.

S2: Good idea! Let's begin! Maybe we'll find out how large that will be.

Continue the dialogue. Write at least one page.

Fig. 2 Translation of the initial dialogue given to each student 
nary dialogues over the year. Every dialogue started with an initial dialogue, which each student had to continue by him- or herself in written form.

The following task together with the written imaginary dialogue of one 11 year old girl, Emma, can also be found in Wille (2011). In that paper the focus is on the activated mathematical self-communication of Emma.

The imaginary dialogue task, shown in Fig. 2, was given at the end of the school year after the students spent several months with the ladder model (cf. Halverscheid et al. 2006) (and other common models for fractions) and with addition and subtraction of fractions.

In Fig. 3 one can see how Emma continued the given dialogue. Thus, Emma was writing both what S1 and S2 said (Fig. 1 shows her original text in German). Both, the initial dialogue and Emma's dialogue were originally written in German and translated by the author.

Fig. 3 Translation of Emma's imaginary dialogue

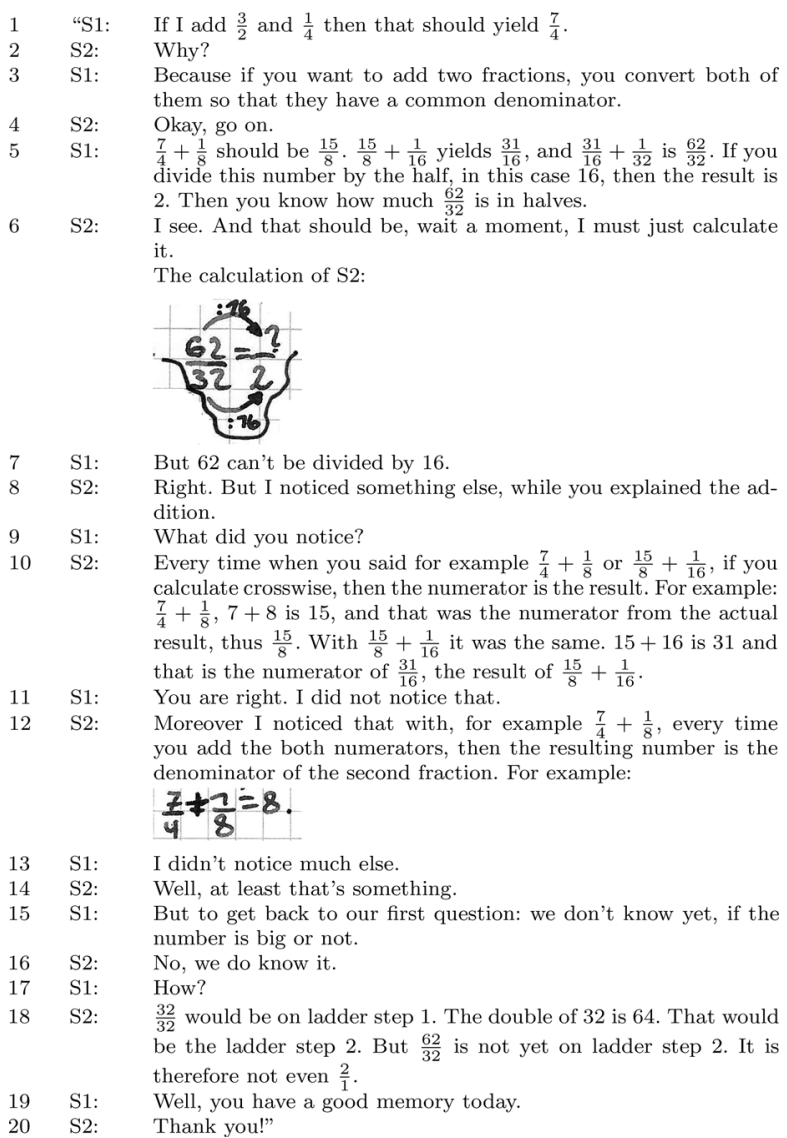




\section{Theoretical Framework}

\subsection{The framework of commognition}

Before writing an imaginary dialogue every student frequently takes part in collective mathematical activities, in particular in real direct dialogues about mathematics. Thus, writing an imaginary dialogue can be seen as the student's individualization ${ }^{1}$ of his or her previous participation. Therefore, a theoretical framework which is founded on a participationists' view of individual development, where collective activities are individualized through participation, like the framework of commognition of Sfard (2008), seems reasonable as the main lens through which to look at imaginary dialogues. In the framework of commogition the term individualization denotes the process of becoming able to "enact individually an activity that previously could only be performed with others" (p. 299, cf. also pp. 76-80). Furthermore, it focuses on the mathematical discourse itself and changes in it in order to reason about thinking as a form of communication and learning as a change in communication. This fits well with the aim of this article, i.e. to elaborate on the relationship between imaginary dialogues and mathematical thinking processes.

The participationists' perspective of Sfard is mainly inspired by the work of Lev S. Vygotsky, who argued that the uniquely human ways of acting arise from perceptible experiences with others (cf. Vygotsky 1978, p. 57; Sfard 2015, p. 130). For instance, Vygotsky describes the development of thinking and speech of children and argues that thinking becomes linguistic and speech becomes intellectual (cf. Vygotsky 2002, p. 155/156).

Accordingly, in the theoretical framework of commognition thinking is seen as an individualized version of (interpersonal) communication, although not necessarily verbal, audible, or visible (Sfard 2007, p. 571; Sfard 2008, p. 81). Considering the processes of thinking and communicating as two "manifestations of the same phenomenon" (p. 296), Sfard uses for both of them the term commognition. For different types of commognition that "draw some individuals together while excluding some others" (p. 91), Sfard uses the notion discourse, whereas a discourse can be called mathematical, if certain keywords, visual mediators, endorsed narratives and routines occur which the community indicates as mathematical (cf. p. 133-134). The discourses are precisely the main unit of commognitive analysis (cf. p. 276).

When investigating a student's mathematical thinking, the problem arises that not the entire multichannel communication is perceptible from the outside or as Sfard states: "mathematical self-communication is difficult to observe" (p. 276). Therefore, the whole communication can only be reconstructed from the observable parts of the discourse without claiming either "authenticity" or "correctness" (cf. p. 276). Sfard illustrates in a diagram (cf. p. 277) a dialogue between two interlocutors as multichannel communication where arrows within the personal channel of an interlocutor denote thinking, while the observable part of the discourse consists of the interpersonal channel, denoted by arrows from one interlocutor to the other. ${ }^{2}$

\footnotetext{
1 Please see below for a definition of the term individualization.

2 Sfard's diagram will later be adapted to imaginary dialogues (see Fig. 4).
} 
Analogously to see thinking as an individualized version of (interpersonal) communication, learning mathematics means an individualization of collective mathematical discourses, thus "the process of becoming able to have mathematical communication not only with others, but also with oneself" (Sfard 2007, p. 572). Therefore, analyzing mathematical learning means investigating changes in students' ways of mathematical communication in order to become a more and more competent participant in the mathematical discourse.

Sfard identifies the "recursivity of linguistic commognition" (p. 116) as one precondition enabling a discourse to grow in complexity. An example of recursivity is communicating-on-communicating, such as "reports on what somebody else has said, remarks on her own thoughts, or reflects on other interlocutors and their communicative actions" (p. 103). Precisely because of the unboundedness of recursion, humans are able to look at communication from the outside in order to reflect, abstract and reason, which is a precondition for changes in how one communicates and as such also for learning (cf. pp. 103ff).

\subsection{Imaginary dialogues within the commognitive framework}

In the framework of commognition an imaginary dialogue that addresses a mathematical task or question is part of the mathematical discourse. Furthermore, a change in this form of mathematical communication with the effect that the student becomes a more competent participant in mathematical discourses with others, indicates a mathematical learning process of the student.

Since in an imaginary dialogue the writer reports and possibly reflects on what a protagonist says, imaginary dialogues are a form of communicating-on-communicating which provides the opportunity to see a discourse from the outside.

Seeing thinking as an individualized version of (interpersonal) communication, on the one hand, and having a student who communicates by him- or herself in the role of two protagonists, on the other hand, entails the question: What is the relationship between the student's thinking and the written imaginary dialogue?

In a comment about her imaginary dialogues, Sarah, a student of grade 5, writes: "With the dialogues I had the feeling that you can now write what you think." This raises the question of whether it is the students' thinking that can be read in an imaginary dialogue. On the one hand, thinking in the commognitive framework is seen as self-communication, as an individualized version of (interpersonal) communication. Furthermore, when a student writes an imaginary dialogue he or she is self-communicating. On the other hand, Sfard takes a nondualist viewpoint on thinking and speech which does not imply that "all thinking is verbal", but "that any speech act is, in itself, an act of thinking" (Sfard 2008, p. 98). Hence, one can argue from this nondualist point of view that the written speech act of composing an imaginary dialogue is part of the student's thinking.

Does this mean that one can always "hear the student's voice" when reading an imaginary dialogue? An imaginary dialogue is a form of written self-communica-

\footnotetext{
${ }^{3}$ The original German text (without correcting misspellings) was: "Bei den Gesprächen hatte ich das Gefühl, dass ich jetzt schreiben kann was ich denke."
} 
Fig. 4 An imaginary dialogue as multichannel communication

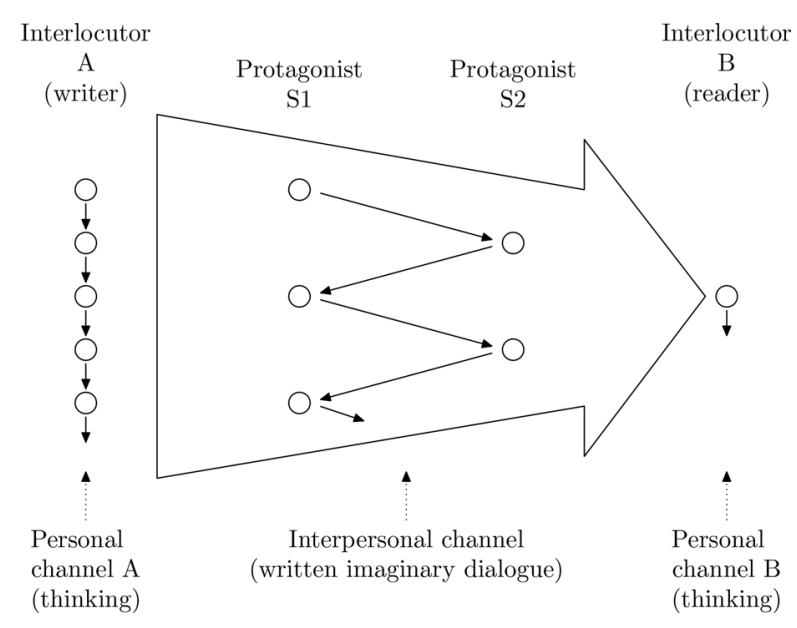

tion, but, in case there is a reader, it is also part of the interpersonal communication between the student as a writer and the teacher or other students as readers of the imaginary dialogue. At this point a first diagram, see Fig. 4, may illustrate the personal and interpersonal channels of the discourse. It is an adaption of Sfard's diagram of a dialogue (cf. p. 277). In order to understand the student's mathematical thinking processes while he or she is writing an imaginary dialogue and how the student's voice enter the imaginary dialogue it is helpful to analyze the large nested arrow in the middle of the diagram regarding the language use (cf. Sect. 4.1), the nesting itself, and particular characteristics of this form of communication that can influence the student's thinking processes (cf. Sect. 4.2).

\section{Theoretical considerations}

The following theoretical considerations concerning the location of an imaginary dialogue between spoken and written language are addressed with the help of a theoretical "wide-angle lens", mainly using the work of Vygotsky, Koch and Österreicher, and Halliday (cf. Sect. 4.1). Furthermore, regarding the particular characteristics of imaginary dialogues, a "zoom-lens" is applied using the theory of speech genres by M. M. Bakhtin (cf. Sect. 4.2). The consequences of these considerations for the use of imaginary dialogues as a method concerning the understanding of mathematical thinking processes will be discussed in Sect. 5.

\subsection{Wide-angle lens: Imaginary dialogues in the range of spoken and written language}

As illustrated in Fig. 4, an imaginary dialogue is written, but its content is a conceived spoken dialogue. Thus, it possesses aspects of spoken and written language. In the past the differences between spoken and written language were outlined in various ways (cf. Vygotsky 1986, 2002; Olson 1977; Ochs 1979; Koch and Öster- 
reicher 1985; Halliday 1989; Albert 2000). In what follows I will elaborate on some of them, i.e on Vygotsky, Koch and Österreicher and Halliday. The aim of the following theoretical considerations is to offer a more complete view of the location of imaginary dialogues between orality and literacy by looking through these different theoretical lenses.

Vygotsky $(1986,2002)$ distinguishes written, oral and inner speech ${ }^{4}$, whereas oral speech serves as a link between written and inner speech (cf. Vygotsky 2002, p. 443). Compared to oral speech, written speech is a "separate linguistic function" (Vygotsky 1986, p. 180). It lacks the "musical, expressive, intonational qualities of oral speech" and is a "speech in thought" (p. 181), a monologue instead of a dialogue with an interlocutor. Vygotsky concludes: "Thus, writing requires a double abstraction: abstraction from the sound of speech and abstraction from the interlocutor" (p. 181).

Certainly, in an imaginary dialogue a real interlocutor is missing. But there are two conceived interlocutors, the protagonists. Therefore, the abstraction from the interlocutor mentioned by Vygotsky seems to be reduced. Thus, it is written speech, but it resembles oral speech.

At this point, to elaborate what exactly "resembles oral speech" means, Bakhtin's notion of utterance is helpful in order to point out precisely the difference between a real and a conceived interlocutor, or between a real dialogue and an imaginary dialogue with conceived protagonists. In Bakhtin's perspective, an utterance is determined by its beginning and end which are determined by the change of the writing or speaking person (cf. Bakhtin 1986, p. 71). Hence, since an imaginary dialogue is written by one author, it is one utterance. An initial dialogue written by someone else is a separate utterance. Moreover, what seemed to be said by a protagonist is not an utterance but a conceived utterance within the one utterance that is the imaginary dialogue, because the change of protagonists is not a change of the writing person. In Fig. 4 the one utterance that is the imaginary dialogue corresponds to the large arrow from A to B, whereas the small arrows between S1 and S2 denote the conceived utterances. Later, in Sect. 4.2, parts of Bakhtin's theory of speech genres will be discussed in more detail.

In the light of Vygotsky again, one can say that an imaginary dialogue is conceived oral speech, because it consists of conceived oral utterances. And therefore, as oral speech serves as a link between written and inner speech, imaginary dialogues might be placed closer to inner speech than written speech without a conceived oral component.

Koch and Österreicher (1985) present a model that provides a differentiated positioning of imaginary dialogues in the range of spoken and written speech. The model distinguishes the language of immediacy and language of distance ${ }^{5}$ on the one hand, and phonic or graphic realization on the other (cf. p. 23). Thus the model combines two axes constituting a multidimensional space. The distinction between phonic and graphic is a dichotomy, but according to the other axis a form

\footnotetext{
${ }^{4}$ Inner speech, also called "inaudible speech" by Vygotsky (Vygotsky 2002, p. 87), corresponds in the cognitive framework to imperceptible individualized intrapersonal speech.

5 In German: "Sprache der Nähe" and "Sprache der Distanz"
} 
of communication is placed in between the language of immediacy and the language of distance depending on how close it is to one or another. For example, a transcript of a conversation is positioned very close to the language of immediacy, although it is written. On the other hand, a prepared talk is positioned close to the language of distance, although it is spoken.

Koch and Österreicher (1985) name various conditions and strategies of verbalization that help to integrate a form of communication into this model. For example intimacy of the interlocutors and face-to-face-interaction would place a form closer to the language of immediacy. In comparison, the unfamiliarity of the interlocutors and separation in place and time are conditions to place something closer to the language of distance.

Again, Bakhtin's notion of utterance helps to integrate imaginary dialogues into Koch and Österreicher's model. Seeing an imaginary dialogue as one utterance, the writer and the reader, i.e. the student and the teacher, are unfamiliar, neither it is faceto-face-interaction. But considering the conceived utterances, an imaginary dialogue has the character of a face-to-face-interaction and also the conceived interlocutors, i.e. the protagonists, are familiar. For the other conditions and strategies named by Koch and Österreicher it can be argued analogously: Seeing an imaginary dialogue as one utterance, its characteristics are close to the language of distance, considering the conceived utterances conditions of the language of immediacy are implemented. Koch and Österreicher, for example, place the communication form printed interview in their model roughly in the middle between the poles immediacy and distances (cf. Koch and Österreicher's diagram on p. 18), since it contains characteristics of both the language of immediacy and of distance. Similarly, an imaginary dialogue can also be positioned between these two poles, possibly closer to the language of distance than the printed (real) interview.

One last strategy of verbalization named by Koch and Österreicher shall be highlighted at this point. They argue that a certain preliminarity and processuality follow from the dialogicity and from minor planning (cf. p. 21).

Halliday (1989) also emphasizes the differentiation between process and product when regarding spoken and written language. According to Halliday, spoken language presents a dynamic view and written language a synoptic one (cf. p. 97). The dynamic view of written language defines its "universe as product rather than as process" (p. 97), as the dynamic view of spoken language defines it. Halliday argues in this regard that "writing creates a world of things; talking creates a world of happening" (p. 93).

Considering again the duality within an imaginary dialogue being one written utterance, but consisting of conceived spoken utterances, I like to rewrite the latter sentence to: Dialogue writing creates the image of a world of happening onto the world of things. Thus, the characteristics of process come into play, although the imaginary dialogue is written.

In sum, with the different theoretical lenses provided by Vygotsky $(1986,2002)$, Bakhtin (1986), Koch and Österreicher (1985), and Halliday (1989), one can locate imaginary dialogues between spoken and written language with different emphases: 
- whether imaginary dialogues are considered as conceived oral speech closer to Vygotsky's notion of inner speech than written speech without a conceived oral component;

- or imaginary dialogues are placed within Koch and Österreicher's concrete model of the language of immediacy and distance;

- or, in the perspective of Halliday, to link the world of happening with the world of things.

Consequences for understanding the students' thinking processes will be discussed in Sect. 5.1 and 5.2.2.

\subsection{Zoom lens: particular characteristics of imaginary dialogues}

The focus will now shift to the particular characteristics of imaginary dialogues. The "zoom-lens" will be provided by M. M. Bakhtin's theory of speech genre.

Bakhtin's theory fits particularly well, because he examines written forms of communication similar to imaginary dialogues, namely, novels and their embedded forms of communication like dialogues and letters. This has an influence on his notion of utterance, on the view of different voices that can enter utterances, and on his notion of speech genre with the distinction in primary and secondary speech genres. Hence, the duality of having one utterance consisting of conceived utterances can be elaborated in detail in order to detect characteristics relevant for the development of the mathematical communication. ${ }^{6}$

\subsubsection{Duality of imaginary dialogues and double reflection}

In the preceding section the duality of an imaginary dialogue became apparent, i.e. being one utterance, consisting of conceived utterances. The duality also comes into play when the following questions are addressed: Who is the addressee of an imaginary dialogue? Which preceding utterances affect what the student is writing or which subsequent utterances are the students anticipating?

Each of these traits affect utterances (cf. Bakhtin 1986, pp. 81-95), thus, they influence the conceived utterances, i.e. utterances of protagonists, within an imaginary dialogue as well - but again they occur in a certain duality:

- Each conceived utterance has dual addressees: On the one hand, the other protagonist is an addressee instead of a real counterpart. On the other hand, each conceived utterance is part of the whole utterance of the imaginary dialogue which has one or more real addressees.

\footnotetext{
6 Certainly other theoretical viewpoints can be appropriate, too. For example the tools of socio semiotics (Halliday 1978, 2004; Morgan 2006) can be relevant, if one wants to understand the social context of an imaginary dialogue. Moreover, for instance Shreyar et al. (2010) used Halliday's systemic functional linguistics (Halliday 2004) as a tool to investigate realized meanings in whole group conversations, thus, if the focus was the realized meanings of an imaginary dialogue, this approach could also be applicable. Bakhtin's approach, in contrast, distinguishes itself through its proximity to the analysis of novels, which provides for recognizing secondary speech genres and voices.
} 
- Subsequent (real) utterances that the writer anticipates affect each conceived utterance within an imaginary dialogue as well as the subsequent conceived utterances. The latter means, that it has an influence on the imaginary dialogue what the writer imagines a protagonist might anticipate as a response of the other protagonist.

- Preceding (real) utterances that the writer has either heard or read affect each conceived utterance within an imaginary dialogue as well as the preceding conceived utterances of the protagonists.

The duality has an additional implication: In a real dialogue the speaker and the listener are two different people, but in an imaginary dialogue the writing student puts him- or herself in the role of both protagonists.

First of all that means that the writing students answers to his or her own conceived utterances. Secondly, a double reflection can occur during the writing process: the writer concretely answers previous conceived utterances while he or she imagines an actively listening protagonist. Here, "actively listening" is understood in the sense of Bakhtin:

For Bakhtin the speaker is not only the active one and the addressee the passive. On the contrary, also listening and understanding are something active and responsive. He describes active understanding as a process of assimilating what is being heard into the "conceptual system" of the listener. Hence, listening is an actively responsive understanding. While someone listens, he or she already prepares an answer, which can also be silent (cf. Bakhtin 1981, p. 282; Bakhtin 1986, p. 68).

Applying this to imaginary dialogues one can conclude: Conceived utterances can be reflected in a double manner by the writer: at the same time explicitly responsive and actively listening.

\subsubsection{Primary and secondary speech genres and properties of direct dialogues}

In an imaginary dialogue, considering the dual addressees, there can be a possible unfamiliarity, thus distance, between the real interlocutors, while the protagonists as fictional students are familiar with each other. In this case a kind of familiar dialogue is part of an unfamiliar one. This correlation can be expressed more precisely by means of Bakhtin's notion of speech genre.

For Bakhtin the "thematic content, style and compositional structure" belongs to the "whole of utterances" and if there are "relatively stable types" of utterances, Bakhtin calls them speech genres (Bakhtin 1986, p. 60) and says that a speech genre is a "typical form of utterance" (p. 87) .

Since an imaginary dialogue is a distinct form of utterance, which is determined by the dialogue form as a conversation between two imagined protagonists, keeping with Bakhtin, imaginary dialogues provide an own speech genre.

Bakhtin distinguishes between primary and secondary speech genres: Primary speech genres are simple and not composed of other speech genres. Secondary

\footnotetext{
${ }^{7}$ Bakhtin's notion of speech genre is closely related to the commognitive term discourse (cf. Sfard 2008, p. 91).
} 
speech genres are complex and composed of transformed speech genres. In what follows I will say a secondary speech genre B embeds a primary speech genre A, if $\mathrm{B}$ is composed of the transformed speech genre A.

An example for primary speech genres is the speech genre of direct dialogues. Examples for secondary speech genres are novels or dramas. A transformed speech genre in a novel could be a dialogue between protagonists or a letter by a protagonist. Here the speaking or writing person does not really change. Also the addressee is still the reader of the novel. Therefore, within the speech genre of a novel one can only speak of a transformed speech genre. Thus, the speech genre of novels embeds the speech genre of direct dialogues.

Analogous, the typical forms of utterances in direct dialogues are embedded in imaginary dialogues, since the author writes conceived utterances of protagonists. Hence, the speech genre of imaginary dialogues is a secondary speech genre, that embeds the speech genre of direct dialogues.

This leads to the question of what are the characteristics of the speech genre of direct dialogues: Bakhtin calls direct dialogues "the simplest and the most classic form of speech communication" (Bakhtin 1986, p. 75) where there is a special linkage between the utterances. Examples of the linkages are: "question and answer, assertion and objection, assertion and agreement, suggestion and acceptance, order and execution" (p. 72).

For Bakhtin these linkages cannot connect sentences that are not utterances, that means they exist only if the speaking or writing person changes. Therefore, inside one utterance these linkages can only occur in a transformed way (cf. p. 72). In other words, if primary speech genres like direct dialogues are embedded into secondary speech genres, a speaker or writer can reply to him- or herself.

Applied to imaginary dialogues this means: Within an imaginary dialogue the conceived utterances are linked to each other as in a real direct dialogue. Linkages such as "question and answer, assertion and objection, assertion and agreement, suggestion and acceptance, order and execution" ( $p$. 72) can occur in a transformed way between the conceived utterances of the protagonists.

\subsubsection{The familiarity of the protagonists}

Bakhtin calls a speech genre where the speaker (or writer) and the addressee are particularly close, a familiar or intimate speech genre, whereby, in intimate speech genres the speaker (or writer) and the addressee are closer than in familiar speech genres. Furthermore, in familiar or intimate speech genres the speaker (or writer) and addressee are "without rank" which leads to a "certain candor of speech" (p. 97). Specifically, in intimate speech genres there is an "atmosphere of profound trust" (p. 97).

Applying this again to imaginary dialogues, if the protagonists are supposed to be students, the direct dialogue belongs to familiar speech genres. The writing student can imagine a certain closeness of the protagonists. Whether it is in intimate speech genres, depends on how the writing student visualizes his or her protagonists. 
Accordingly, it can be said: Imaginary dialogues written by students in mathematics education, where the protagonists are supposed to be students as well, embed familiar speech genres and possibly intimate speech genres.

\subsubsection{Reverberations of other utterances}

Finally, the focus is shifted one more time to the preceding utterances that affect each utterance: Bakhtin describes that "each utterance is filled with echoes and reverberations of other utterances", moreover, "every utterance must be regarded primarily as a response to preceding utterances of the given sphere" (p. 91).

Similarly, in an earlier essay he speaks of diverse ways of speaking in novels (cf. Bakhtin 1981, p. 324ff; Morson and Emerson 1990, p. 124). Different voices, i.e. the speaking personalities or consciousnesses (cf. Bakhtin 1981, p. 434) may be "heard" and can come into contact. On the one hand, the speaking person can be incarnated in a character (cf. p. 335), but different voices can also be interwoven or "reciprocally permeable" in one speech, they can be "brought close to another, made to overlap", they can "partially intersect one another, creating the corresponding interruptions in areas of intersections" (Bakhtin 1984, p. 239; cited in Morson and Emerson 1990, p. 344). In particular, the discourse given to a character can be the authors' own discourse. That way the characters' speech "always sounds together with authorial speech" or the character has his own differing "perception of the world that is incarnated in his action and his discourse" (Bakhtin 1981, p. 335).

Regarding imaginary dialogues, there are protagonists similar to characters in novels. Therefore one can say: Echoes and reverberations of other utterances fill an imaginary dialogue. In particular, different voices, including the author's, can enter the protagonists' conceived utterances.

In sum, the "zoom-lens" of Bakhtin's theory of speech genre revealed several particular characteristics: the duality of an imaginary dialogue regarding the addressee, subsequent and preceding utterances, the possible double reflection, the distinction between primary and secondary speech genres, i.e. in this case having the familiar speech genre of direct dialogues embedded, and the impact of reverberations of other utterances. These theoretical findings will be applied in Sect. 5.2 and illustrated in Sect. 6.

\section{Approaching students' mathematical thinking processes}

In this section, the potential and limitations of imaginary dialogues as a method to approach students' mathematical thinking processes is discussed (cf. the main question in Sect. 1), refering specifically to the insights of the preceding two sections. A number of short examples are already presented here and references provided to further examples in Sect. 6 in order to illustrate the line of argumentation.

In Sect. 3 it was argued that within the framework of commognition and its nondualist viewpoint of thinking and speech, where any speech act is seen as an act of thinking, the written imaginary dialogue is part of the student's thinking. The particular form of dialogue influences the written speech and therefore can affect 
the mathematical thinking process of the student. Thus, it affects the mathematical thinking processes that can be understood by analyzing an imaginary dialogue. Therefore, in Sect. 5.1 and 5.2 the focus will alternate between how the characteristics of imaginary dialogues can affect the student's mathematical thinking and the consequences for the understanding of the thinking processes. This section closes with considerations on how to use and analyze imaginary dialogues (cf. Sect. 5.3).

\subsection{Consequences based on the location of imaginary dialogues between written and spoken language}

Imaginary dialogues are considered to be located between spoken and written language as was discussed in Sect. 4.1 from a number of different viewpoints.

On the one hand, one can argue that imaginary dialogues have the potential to serve as a bridge between spoken and written mathematical communication: Since imaginary dialogues are close to spoken dialogues between students, the language barrier could be experienced as rather low, except for very young students who are in the process of learning how to write 8 . In the light of Vygotsky, the "abstraction from the interlocutor" is missing, but the "abstraction of the sound of speech" still must be managed. That way this written form of mathematical communication has the potential to change using aspects of the spoken language.

On the other hand, from the perspective of Halliday, one can take the adapted phrase "Dialogue writing creates the image of a world of happening onto the world of things" (cf. Sect. 4.1) into account to argue that an imaginary dialogue can enable a connection between the dynamic view of spoken language and the synoptic view of written language. In this way, and also in keeping with Koch and Österreicher's concept of dialogicity, the processuality of spoken language comes into play. (In Sect. 5.2.2 the processuality embedded in imaginary dialogues will be taken up again.) Therefore, using imaginary dialogues offers the potential to understand those thinking processes associated with the development of both written and oral aspects of a student's mathematical language.

An example of the development of the mathematical discourse can be found in the author's study on the conception of central notions in elementary algebra (Wille $2008,2010)$. Within the imaginary dialogues of students one can observe how the students' use of the notion of variable changes, sometimes within a single imaginary dialogue and sometimes after several dialogues.

\subsection{Consequences based on the particular characteristics of imaginary dialogues}

\subsubsection{Perceived distance and proximity}

As discussed in Sect. 4.2.1 duality exists in one written utterance that is composed of conceived spoken utterances from an imagined face-to-face dialogue. As a conse-

\footnotetext{
8 See Sect. 7 for further discussion regarding the question of how students can conceive language demands when writing an imaginary dialogue.
} 
quence, the two poles proximity and distance that were already connected to spoken and written language come into play again, here, regarding the student's perception of his or her imaginary dialogue: The writer puts him- or herself into the role of both protagonists, while at the same time it is possible to distance oneself from the protagonists: a consequence of having a secondary speech genre.

Distancing oneself from the protagonists has consequences: The writer's perception of changing solutions (cf. Sect. 6.2) and of committing errors within an imaginary dialogue can change in contrast to utterances directly addressed to the teacher. For example, an 11 year old girl Nina, writes in a comment about her imaginary dialogues:

You could not do anything wrong, because you had to invent yourself what S1 and S2 would say.

One reason for Nina's way of thinking could be that she puts distance between herself and the protagonists. If the protagonists do something "wrong", in her words, it is not Nina herself who is doing this.

Furthermore, the writer obtains a "look from the outside" which in Sfard's perspective is a precondition for reflecting, abstracting and reasoning and therefore for a change of discourse. This involves the potential that the conceived utterances of the protagonists can be reflected in a double manner by the student who writes an imaginary dialogue: at the same time explicitly responsive and actively listening. Thus, there is the possibility that an intense reflection process can be initiated. An example of double reflection will be discussed regarding Emma's imaginary dialogue in Sect. 6.1.1.

As regards the proximity, it is possible that students perceive themselves as being able to write what they think, as seen with Sarah (in Sect. 3.2). Furthermore, having a familiar and possibly intimate speech genre embedded implies the potential:

- for the conceived utterances to show a greater candor than if the student is only directly writing to the teacher.

- for questions to be asked as if they are directed at a counterpart of the same rank.

- for answers to be given as if they explain something to another student.

This has an effect on the writing process. As in a real dialogue with another student, the writing student can try out different solution processes within the dialogue, including those where the writer does not know if they will reach a solution (cf. Wille 2009b).

In terms of understanding mathematical thinking processes it can be stated that by using imaginary dialogues there is the potential to read a student's mathematical considerations which can show a certain candor, where the student might have less fear of committing errors, and where different solutions can be tried out and also be changed again.

\subsubsection{Processuality}

The familiar speech genre of the conceived dialogue allows for the student to explain as if explaining to another student how a task can be solved or how he or she reflects 
on a mathematical notion. Here, again, the processuality of spoken language comes into play. For example "spoken instructions" can be part of the embedded dialogue as Halliday describes them to be "usually easier to follow, provided they are timed to fit the task" (Halliday 1989, p. 99). For the writing student this has the potential for him or her to become more aware of how to understand a mathematical issue or at what point there are difficulties in the understanding. Therefore, processuality can be considered as a positive element of this method, when the interest is in those processes in which the students explain how they understand an issue in a reflected way or how a single student deals with a new topic.

The latter can be seen in a further study conducted by the author (Wille 2009a) where students face the problem of how to add fractions with different denominators if the addition with the same denominators is already known. Moreover, the processuality is illustrated by Emma's imaginary dialogue in Sect. 6.1.2. Another example is the following: A grade 5 student, Lydia, writes in her imaginary dialogue about expanding and reducing fractions. In her dialogue she explains not only why there is an equal sign but how she imagines the equality in the ladder model ${ }^{9}$ :

S1: Okay, but why is there an = sign?

S2: I wrote the $=$ sign there, because that way I know that $\frac{1}{2}$ and $\frac{3}{6}$ have indeed different numbers, but they are on the same height. You can have a look at the picture again. (...)

In this excerpt we also see how written and spoken language merge together: When Lydia writes "I wrote the = sign there", one can "hear" the spoken word "equal sign", but at the same time read the written sign "=".

\subsubsection{Different voices}

It was argued that the embedded speech genre of direct dialogues (cf. Sect. 4.2.2) has the consequence that conceived utterances are linked to each other as in a real dialogue. That means that the writer is prompted to answer and question his or her own sentences over and over again in the form of conceived assertions, arguments, responses, questions, answers, and rejoinders. This in turn implies the potential for the tension between different ways of thinking to be put into play, for example by giving the protagonists differing voices.

At this point the question (cf. Sect. 3.2) whether one can "hear" all the time the student's voice is taken up again and must be negated. The form of an imaginary dialogue allows the student to let multiple voices in Bakhtin's sense enter the dialogue (cf. Sect. 4.2.4). Hence, a protagonist can embody one or several voices.

In one of the author's previous studies, for example, a student reproduced in his imaginary dialogue a real dialogue he had had with another student. In the real dialogue he explained the meaning of variables in certain terms to the other

\footnotetext{
9 The German original text (without correcting misspellings) was: "Das = Zeichen habe ich dort hingeschrieben, weil ich dann weiß, das $\frac{1}{2}$ und $\frac{3}{6}$ zwar unterschiedliche Zahlen haben, aber auf der gleichen Höhe sind. Das kannst du dir noch einmal auf dem Bild ansehen."
} 
student who had difficulties with it. Afterwards, in the imaginary dialogue, both protagonists seemed to correspond to one of each student: One protagonist had the same difficulties as the other student before and the second protagonist explained it to him. In contrast, within other examples, it seemed like both protagonists embody the same voice that tries to solve a task by alternating between asking and answering questions. Altogether, there are three cases and numerous intermediate forms of them: The student who writes the imaginary dialogue sees him-or herself as one of the protagonists, as both protagonists or as neither.

Nevertheless, this mathematical communication, in the light of commognition, is part of the student's mathematical thinking, where the writing speech act is itself an act of thinking. Moreover, as Bakhtin sees "inner speech" as "a complex orientation among voices and dialogues that we have internalized and brought into interaction" (Morson and Emerson 1990, p. 343), in an imaginary dialogue the way a student brings his or her own and other voices into interaction about a mathematical task or question is part of the student's mathematical thinking.

To summarize, using imaginary dialogues offers the potential to understand how a student brings the tension between different voices into play, while this also proves a limitation in that it becomes difficult to identify and differentiate the voices.

\subsection{Using and analyzing imaginary dialogues}

This section looks at suitable aims that can be addressed with this method, how this method differs from other methods associated with understanding mathematical thinking processes, and outlines some of the possibilities when it comes to analyzing the writings. In addressing these particular aspects complete answers are not provided, but this represents a starting point.

When analyzing an imaginary dialogue, one examines written mathematical communication of one student that is a conceived spoken dialogue of protagonists imagined by the student. In the commognitional framework, analyzing means reconstructing (parts of) the whole multichannel communication from the observable parts (cf. Sect. 3). Visualized in Fig. 4 this can be described as the attempt to reconstruct the arrows of the personal channel of A with the help of the arrows going from one protagonist to the other.

The aimc an be, for instance, to investigate the use or the change of keywords, visual mediators, endorsed narratives or routines in order to explore the learning process. As an example, a study that investigated changes in the conception of central notions in elementary algebra (Wille 2008, 2010) was previously mentioned above. Moreover, in Emma's imaginary dialogue (see Fig. 3) one can explore, for example, which endorsement routine Emma uses to explain her findings: Concerning the mathematical patterns which she detects in her calculations, the endorsement is based on validations concerning the concrete calculations.

As argued in Sect. 4.1, because of the middle position between orality and literacy there is a certain closeness to natural communication. But, in contrast to a transcript of a real dialogue in an imaginary dialogue individual processes can be traced. Since it is a written single work with no interruption, there is no external input in between as there is, for instance, in interviews or real interaction of students. Furthermore, 
similar to other forms of mathematical writing, the process of writing an imaginary dialogue involves a slowdown of thinking processes (cf. Sect. 7).

However, depending on the specific research question, in the analysis one has to deal with the duality of imaginary dialogues of being one written utterance composed of conceived spoken utterances from an imagined direct dialogue. In particular, there is the possibility of having different voices entering the conceived utterances (cf. Sect. 4.2.4 and 5.2.3). Therefore one cannot proceed on the assumption that the transcript is a "recorded social situation" as for example is the case within interpretative classroom research (Krummheuer 2000). Furthermore, if using, for example, lineby-line microanalysis (cf. Strauss and Corbin 1998), one cannot directly discuss "how the person quoted has used single words, phrases, and sentences" (p. 60), since no real person is quoted.

If the focus is mainly on the change of communication, i.e. the change of keywords, visual mediators, etc., then detecting the own voice of the student who writes the imaginary may be less important.

Detecting different voices, on the other hand, can be seen as a potential of imaginary dialogues to investigate pictures that students have about mathematics or learning mathematics. For example, in an imaginary dialogue of a 10 year old girl one may "hear" the reverberation of utterances about how to deal with open questions in the mathematics classroom in her last sentence, when she writes: "But the question 'why this is like this?' I cannot answer. You have to take it."10

In instances where the aim is to recognize the author's voices, for example, triangulation may be used. For example, having nothing but a video taken from the writing process can reveal at some points where the author's voice can be heard. For example one girl, Fatma, wrote in her imaginary dialogue:

S2: Hmm. This is really difficult now. I must think about it now. I have really no idea left, I think it works best, if one can $1 \cdot 1$. Otherwise I have no idea, do you have an idea maybe?

S1: Not a clue, must think about it, too. Hmmm ...I find it best, if they are divisible (...)

In the video taken from her writing process one can see that when Fatma finished the sentence "I must think about it now" she paused for 37 seconds and after writing "Hmmm ..." she paused for 16 seconds. Hence, "I must think about it now", can be assumed to be said with her own voice ${ }^{11}$.

Furthermore, in the study where Emma's imaginary dialogue is taken from, on some occasions stimulated recalls were conducted. In the stimulated recall the student saw a video taken from his or her writing process. The video was often stopped by the interviewer to ask what the student had been thinking about in this

\footnotetext{
10 The original German text was: "Aber warum das so ist, kann ich dir nicht erklären. Das musst du so hinnehmen."

11 By "1 - 1" Fatma probably means the multiplication table, in German: "Einmaleins". The original German text was: "wenn man $1 \cdot 1$ kann."
} 
moment, why the student had written what he or she had written and when the student had had the different ideas.

At this point, it is not the aim to exhaustively discuss possible methods of analysis, because this depends on the concrete research question of a study and would go beyond the scope of this article. Instead one exemplary approach is presented by which Emma's dialogue is analyzed in the following Section: To differentiate between the view of the protagonists and of the student who writes the imaginary dialogue one possibility is to conduct the analysis in two layers:

Layer 1: At first, the conceived utterances are considered as if they were real utterances between actual interlocutors.

Layer 2: Secondly, the conceived utterances are seen as what they are, thus written by the real student who imagined what the protagonists might say.

For layer 2 data from a possible triangulation can be taken into account as well.

Finally, it can be stated that using an imaginary dialogue is a method to investigate students' mathematical perceptions without the need for transcription. In contrast to real dialogues, no other person restricts the process of mathematical communication and in contrast to the method of thinking aloud (cf. e.g. Shreyar et al. 2010; Leuders et al. 2011) the imaginary dialogue is written and mathematical perceptions are explained as if to another student. Additionally, the students can bring the tension between different voices into play and has the possibility to either perceive themselves in close proximity to or at a distance from the writing. Moreover, as previously argued, if the focus is on the student's own voice, triangulation is a reasonable choice of method to use.

\section{Illustrating examples}

In this section Emma's imaginary dialogue and a student's comment will serve to exemplify the considerations above.

\subsection{Emma's imaginary dialogue}

In a two layer analysis (see Sect. 5.3) of Emma's imaginary dialogue two questions will be addressed: How double reflection can be observed in the writing process and which possible effects can be seen in Emma's imaginary dialogue that might follow from the embedded familiar speech genre. Emma's spoken utterances of her stimulated recall will be considered in layer 2 in addition to her imaginary dialogue.

The questions which and how mathematical ideas are developed by Emma are elaborated in Wille (2011).

\subsubsection{Double Reflection}

Concerning double reflection (see Sect. 4.2.1) the questions to be analyzed are: 
- Where do the protagonists listen in the sense of actively responsive understanding? (layer 1)

- Can it be observed that Emma reflected in a double manner on conceived utterances? (layer 2)

\section{Layer 1 At row 8 the protagonist S2 says:}

But I noticed something else, while you explained the addition.

Thus, while S1 was explaining an addition, S2 noticed something else. Because this was the only place where S1 explained an addition, S2 might refer to S1's explanation in row 5. In particular, in row 10 the protagonist S2 explains what she noticed, namely a certain property of the sums: In each addition, $\frac{7}{4}+\frac{1}{8}=\frac{15}{8}$ and $\frac{15}{8}+\frac{1}{16}=\frac{31}{16}$, if one adds the numerator of the first summand with the denominator of the second summand, the result will be the numerator of the result ${ }^{12}$.

Therefore, it can be assumed that while S1 was explaining the addition, S2 was listening actively in the sense of responsive understanding. In particular, S2 took an "active, responsive attitude" (Bakhtin 1986, p. 68), because within the process of understanding what S1 explained, S2 was noticing a mathematical property within the sums. Thus, S2 was preparing an answer that can later be read in row 8 and 10 .

Layer 2 Now, in layer 2, I will consider that Emma imagined and wrote what S1 and S2 said. In the stimulated recall Emma said:

Here (she points at row 1) I did not notice it, but while I was writing this (she points at row 5), I looked at this carefully one more time and then I noticed it.

Therefore, it can be assumed that while Emma was writing row 5, where S1 explains the addition of different sums, she was also actively listening in the role of S2 and thereby noticed the mathematical property of the sum.

Consequently, Emma reflects on a conceived utterance in a double manner. She explicitly writes what one protagonist says and at the same time she actively listens in the role of the other protagonist and prepares an answer. Hence, this is an example of the double reflection mentioned in the preceding section.

\subsubsection{Familiarity}

Concerning embedded familiar speech genres (see Sect. 4.2.3) the questions to be analyzed are:

- Which possible effects can be seen that might follow from the embedded familiar speech genre? (layer 1)

- What are consequences for the writing student Emma? (layer 2)

Layer 1 In row 2 the protagonist S2 asks the question "Why?" which is answered in row 3 without judgment. Also, in row 9 S1's question "What did you notice?" shows an interest to get to know what S2 observed. Thus:

12 This property can be shown by induction. 
Questions are asked and directed to a counterpart of the same rank.

Furthermore, in the dialogue there are two different approaches to get to know how big the resulting number $\frac{62}{32}$ is, that $\mathrm{S} 1$ gets in row 5 . The little arithmetical error of writing $\frac{62}{32}$ instead of $\frac{63}{32}$ is not that important for the following dialogue. The first approach to estimate the size of $\frac{62}{32}$ can be seen in rows 5 to 8 . In row 5 the protagonist $S 1$ has the idea to reduce the number $\frac{62}{32}$ to a fraction with 2 as the denominator. S2 picks up this idea in row 6, but S2's calculation leads to a question mark. Consequently, S1 objects to this approach in row 7 by saying "But 62 can't be divided by 16" and S2 agrees in row 8. Accordingly, this first approach does not reach a solution. Moreover, no personal judgment of one or the other protagonist can be read in the dialogue.

The second approach can be seen in rows 15 to 19 . In row $15 \mathrm{~S} 1$ picks up the question again whether the resulting number is big or not. Then, in row $18 \mathrm{~S} 2$ explains with the help of the ladder model that $\frac{62}{32}$ is not even 2 by identifying $\frac{32}{32}$ with the ladder step 1 and $\frac{64}{32}$ with ladder step 2 . Thus, the second approach reaches an answer to the beginning question. Consequently, one can summarize that:

\section{Different solution processes are tried out within the dialogue.}

Finally, at the end of the dialogue S2 states that she knows whether the (resulting) number is big or not. In response, S1 asks in row 17 "How?"13. Thus, the explicit question is not 'What do we know?', but 'How do we know?'. After that S2 explains in row 18 that $\frac{62}{32}$ is not even 2 together with the explanation of how to reach this answer with the help of the ladder model. Hence:

At this point, the protagonists explain how they understood something instead of only what they understood.

All of the above, i.e. that questions are asked and directed to a counterpart of the same rank, that different solution processes are tried out within the dialogue and that at some places the protagonists explain how they understood something instead of only what they understood, can be seen as indicators for a certain candor of speech within the dialogue which might be a consequence of the embedded familiar speech genre.

Layer 2 The above findings in layer 1 conclude that Emma asked and answered questions in the role of her protagonists as if they were directed to a counterpart of the same rank. Moreover, Emma tried out different solution processes. In the stimulated recall, it can be seen that Emma was herself in the process of finding an answer to the question of how big her resulting number $\frac{62}{32}$ was. There she explained about the first approach:

To see how big that is, I wanted to come back to halves.

13 In the German original text S1 asks: "Wie denn?" 
Since Emma says "I", it can be concluded that she herself wanted to come back to halves and therefore let her protagonists in rows 5 and 6 carry this out. Later she added:

For the time being it did not work.

Therefore, the question mark that the protagonists met was the same for Emma. The interviewer also asked at which point Emma thought about the second approach that led to an answer. And she said:

While I was writing.

The preceding leads to the conclusion that Emma tried out different solution processes within her imaginary dialogue, including ones where she did not know if she would reach a solution.

Above, in layer 1, it was mentioned that the protagonists explain how they understood something instead of only what. An explanation for this can be that the conceived utterances have an imagined student as an addressee who could need or at least could appreciate explanations of the 'how'.

How Emma put her protagonists into play can also be seen in the stimulated recall, where she said about her writings in row 2 :

There I thought about what S2 could say. So I chose 'Why?'.

This "Why" is not a direct prompt of the task, since the initial dialogue leaves open whether one of the protagonists asks a lot of questions or not. Since relations like question and answer are common in direct dialogues, the preset dialogue form could entail that students frequently write questions in their imaginary dialogues. Thus, because Emma thought that S2 could ask 'Why?' she prompted herself to write an explanation in row 3 .

Additionally, it can be assumed that by writing about the how and the why, Emma becomes more aware of it. An example was already row 8 and Emma's explanation in the interview (cf. layer 2 in Sect. 6.1.1).

Furthermore, the reader of Emma's dialogue has the opportunity to learn about how Emma understands something, for example, how she comes to an answer to the question of how large her resulting number is and that here she uses the ladder model to picture fractions.

\subsection{The "look from the outside": a student's perception of changing solutions}

An additional property of imaginary dialogues will be briefly exemplified below: the students' perception of changing solutions (see Sect. 5.2). Olga, an 11 year old girl writes in a comment at the end of the year on the above mentioned project:

Above all you could change your solution again as in a conversation, different than in class. 
Later she adds:

As I said, you could change your opinion straight away. For example if one said: ' $1+1=3$. Oh, no. I mean 2.' If one had said this in class, maybe it would not have been apparent and it would have been an embarrassing mistake. This already happened to me twice. Straight away I could say or write that this is wrong and that there must be a different solution.

Here one can see that Olga appreciates how she can change solutions in the imaginary dialogue and thereby can avoid what she calls a mistake. Moreover, Olga might see a distance to the protagonists and at the same time a certain proximity to them. The latter could be seen above in Olga's comment where she writes about her solution that she could change. That way the protagonists can carry out the solution processes of the writer and at the same time put the writer in a position that is distanced from the solution process.

\section{Discussion}

The previous discussion aimed at revealing the potential and limitations of imaginary dialogues with regard to understanding students' mathematical thinking processes (cf. Sect. 5).

The two poles of proximity and distance were evident in the language and represented a potential for the student to either allow proximity to his or her own voice or put a distance between him- or herself and the protagonists when needed. Furthermore, the dialogue form allows the student to reflect in a double manner and to let the processuality of spoken language enter the writing. In this way imaginary dialogues can be used to investigate the students' mathematical thinking processes with a lens different to other methods.

Over the course of the discussion, it was argued that language use and the particular characteristics of imaginary dialogues can possibly affect the student's mathematical thinking process. Thus, imaginary dialogues could be used not only to understand mathematical thinking processes, but also to support mathematical learning processes. According to the framework of commognition this involves supporting changes in students' ways of communication in order for them to become a more and more competent participant in the mathematical discourse.

This leads to the question of how imaginary dialogues differ from other forms of mathematical writing which emphasize the aim to support the mathematical learning process. In the following discussion attention is turned to this question.

\subsection{Differences between imaginary dialogues and other forms of mathematical writing}

Building on the idea "Writing-to-learn" (cf. Emig 1977; Morgan 1998, p. 25), different forms of mathematical writing developed (cf. e.g. Burton 1985; Borasi and Rose 1989; Selter 1994; Gallin and Ruf 1998; Shield and Galbraith 1998; Clarke et al. 1993; Fetzer 2007). Examples are free writing, creative writing, journal writing. 
When comparing these forms of mathematical writing with imaginary dialogues with regard to the mathematical learning process it is necessary to take into account that the studies had diverging aims. For example, in the study of Selter (1994) the students' own written products of an elementary school were investigated with regard to their co-creation of productive learning processes. In contrast, Fetzer (2007) investigated among other things how the students' writing and the publishing processes of their writing affected their mathematical learning.

Many studies have in common that several positive effects on mathematical learning processes were discussed. For example Borasi and Rose (1989) describe advantages for students and teachers if the students write journals, which means logs or personal notebooks, "where students can write down any thought related to their mathematics learning" (p. 348). They suggest that "the use of writing to learn can provide a valuable means to facilitate a personalized and making-of-meaning approach to learning mathematics" (p. 347). Furthermore, Gallin and Ruf (1998) explore travel journals ${ }^{14}$ in order to enter into a dialogue between the teacher and the writing student. They compare writing and speaking processes and state that the writing processes are slower and enable students to be more aware of them. And a positive effect for the mathematical understanding is described by Shield and Galbraith (1998). They distinguish two categories of writing: journal writing and expository writing and they argue that "writing about a mathematical idea can be an elaborative process which has the potential to enhance understanding" (p. 36).

Not all findings can be readily transfered to imaginary dialogues, since it depends for example on the concrete aim of the study and as such on the concrete learning environment in which the forms of mathematical writings are deployed. Nevertheless, the learning environment can be adapted. As for example imaginary dialogues of students and responses of teachers can perpetually follow one another. In this way a similar mathematical discourse to Gallin et al.'s dialogue by travel journals could develop.

Additionally the imaginary dialogue task itself can vary in different ways. For example, in the author's study (Wille 2011), from which Emma's imaginary dialogue was taken from, two different categories of tasks were posed: Some of them were exploratory tasks, where the initial dialogue contained a mathematical question or task to discover (or rediscover) something that is new to the student, and some were reflection tasks, where the initial dialogue contained a request to reflect on a mathematical issue that the writing student was already familiar with.

Nonetheless, the differences that remain are the particular characteristics (cf. Sect. 4.2). Compared to the other forms named above, the student who writes an imaginary dialogue is explicitly asked to write in dialogue form. That implies having a secondary speech genre in Bakhtins perspective or communicating-oncommunicating in the framework of commognition.

This does not mean that an internal dialogue with characteristics of a direct dialogue could not occur in journal writing. For example Clarke, Waywood, and Stephens (1993) addressed the question which mode of mathematical writing is particularly helpful for students. They analyzed in a four year study students'

14 In German: Reisetagebücher 
journals for classes 7 to 12 . They distinguish between three modes of mathematical writings which they call Recount, Summary and Dialogue, where Dialogue means an internal dialogue:

Finally, some students appeared to move beyond this to an internal dialogue, where they began to pose questions and hypotheses concerning the mathematics in which they were engaged. (p. 243)

They describe that "in the Dialogue mode, students begin to focus on the 'ideas' being presented" (p. 248). Moreover, "in this mode, students are able to identify and analyze their difficulties, suggesting reasons why they are thinking in a certain way" (p. 248).

Here, it is apparent that a student can put characteristics of a direct dialogue into his or her journal entry like posing and answering questions that were considered as valuable and therefore the teachers in their study encouraged the students to write their journals in the internal Dialogue mode. However, a difference between imaginary dialogues and journal writing is that an imaginary dialogue is set up in the form to embed a direct dialogue. Moreover, an additional difference still remains: putting oneself explicitly in the role of two protagonists is different from having an internal dialogue without the possible distance that can be put to both of the imagined protagonists. That means consequences like seeing communication from the outside or differences in the perception of committing errors or changing solutions seemed to be more linked to imaginary dialogues than to journal writing where Dialogue mode is encouraged.

\subsection{Further research and open questions}

As regards further research, various directions could be taken, whether it be the focus on understanding thinking processes or supporting learning processes. For example one focus might be the development of mathematical language proficiency. Morgan et al. (2014) state that "much less attention has been paid to the question of how children learn to speak or write mathematically or to what kinds of mathematicallinguistic competence may be developed in the home, in pre-school settings and in other non-school settings" (p. 851). This is also underpinned by the findings of Prediger et al. (2015) that "language proficiency is the background factor with the strongest connection to mathematics achievement, among all social and linguistic background factors" (p. 77). Thus, one can pose the question how the middle position between written and spoken mathematical discourse of imaginary dialogues can be utilized to support the development of mathematical language proficiency, for example, in children with a bilingual background.

A related question is for what reasons students may perceive language demands as rather low when writing an imaginary dialogue and for whom it might be difficult. Here, further research could be fruitful using systemic functional linguistics (Halliday 2004) to examine the relation between register change and the students' perception.

Furthermore, to contrast the use of imaginary dialogues with other methods that aim to better understand students' thinking processes, further studies could be appropriate that use methods like thinking aloud or dyad (cf. Leuders et al. 2011) and 
additionally imaginary dialogues as triangulation in order to emphasize differences. Additionally, imaginary dialogues can be used in pre-service teacher education in order to initiate reflection processes (cf. Wille 2016) and to support didactical and mathematical learning.

Finally, further areas of interest include what conditions are conducive to maximizing the potential of imaginary dialogues and what the consequences of using imaginary dialogues in class for the teacher are.

Open access funding provided by University of Klagenfurt.

Open Access This article is distributed under the terms of the Creative Commons Attribution 4.0 International License (http://creativecommons.org/licenses/by/4.0/), which permits unrestricted use, distribution, and reproduction in any medium, provided you give appropriate credit to the original author(s) and the source, provide a link to the Creative Commons license, and indicate if changes were made.

\section{References}

Albert, L. R. (2000). Outside-in - inside-out: seventh-grade students' mathematical thought processes. Educational Studies in Mathematics, 41, 109-141.

Bakhtin, M.M. (1981). The dialogic imagination, four essays. Austin: University of Texas Press. M. Holquist \& C. Emerson, Trans.

Bakhtin, M. M. (1984). Problems of Dostoevsky's Poetics. Minnesota: University of Minnesota Press. C. Emerson, Ed. and Trans.

Bakhtin, M.M. (1986). Speech genres and other late essays. Austin: University of Texas Press. V. W. McGee, Trans.

Borasi, R., \& Rose, B. J. (1989). Journal writing and mathematics instruction. Educational Studies in Mathematics, 20(4), 347-365.

Burton, G. M. (1985). Writing as a Way of Knowing in a Mathematics Educational Class. Arithmetic Teacher, 33(4), 40-45.

Clarke, D. J., Waywood, A., \& Stephens, M. (1993). Probing the structure of mathematical writing. Educational Studies in Mathematics, 25(3), 235-250.

Emig, J. (1977). Writing as a Mode of Learning. College Composition and Communication, 28(2), $122-128$.

Fetzer, M. (2007). Interaktion am Werk. Eine Interaktionstheorie fachlichen Lernens, entwickelt am Beispiel von Schreibanlässen im Mathematikunterricht der Grundschule. Kempten: Klinkhardt.

Gallin, P., \& Ruf, U. (1998). Spuren legen - Spuren lesen. Dialogisches Lernen im Mathematikunterricht, vol. 2. Seelze: Kallmeyer.

Halliday, M. (1978). Language as social semiotic: The social interpretation of language and meaning. London, UK: Edward Arnold.

Halliday, M. (1989). Spoken and written language. Oxford, UK: Oxford University Press.

Halliday, M. (2004). In An introduction to functional grammar. London, UK: Edward Arnold. rev. ed. Matthiessen C. M. I. M. (Ed.).

Halverscheid, S., Henseleit, M., \& Lies, K. (2006). Rational numbers after elementary school: realizing models for fractions on the real line. In J. Novotná, H. Moraová, M. Krátká \& N. Stehlíková (Eds.), Proceedings of the 30th Conference of the International Group for the Psychology of Mathematics Education (PME30) (vol. 3, pp. 225-232). Prague, Czech Republic: PME.

Koch, P., \& Österreicher, W. (1985). Sprache der Nähe - Sprache der Distanz. Mündlichkeit und Schriftlichkeit im Spannungsfeld von Sprachtheorie und Sprachgeschichte. In O. Deutschmann et al. (Ed.), Romanistisches Jahrbuch (vol. 36, pp. 15-43). Berlin/New York: Walter de Gruyter.

Krummheuer, K. (2000). Interpretative research in primary mathematics education. ZDM - The International Journal of Mathematics Education, 32(5), 124-125.

Lakatos, I. (1976). Proofs and Refutations: The Logic of Mathematical Discovery. Cambridge: Cambridge University Press.

Leuders, T., Naccarella, D., \& Philipp, K. (2011). Experimentelles Denken - Vorgehensweisen beim innermathematischen Experimentieren. Journal für Mathematik-Didaktik, 32(2), 205-231.

Morgan, C. (1998). Writing Mathematically. The Discourse of Investigation. London/Bristol: Falmer Press. 
Morgan, C. (2006). What does social semiotics have to offer mathematics education research? Educational Studies in Mathematics, 61(12), 219-245.

Morgan, C., Craig, T., Schuette, M., \& Wagner, D. (2014). Language and communication in mathematics education: an overview of research in the field. ZDM - The International Journal of Mathematics Education, 46(6), 843-853.

Morson, G., \& Emerson, C. (1990). Mikhail Bakhtin, Creation of a Prosaics. California: Standford University Press.

Ochs, E. (1979). Planned and unplanned discourse. In T. Givon (Ed.), Discourse and syntax. Syntax and Semantics Series (vol. 12, pp. 52-80). New York: Academic Press.

Olson, D. R. (1977). From Utterance to Text: The Bias of Language in Speech and Writing. Harvard Educational Review, 47(3), 257-281.

Prediger, S., Wilhelm, N., Büchter, A., Gürsoy, E., \& Benholz, C. (2015). Sprachkompetenz und Mathematikleistung - Empirische Untersuchung sprachlich bedingter Hürden in den Zentralen Prüfungen 10. Journal für Mathematik-Didaktik, 36(1), 77-104.

Selter, C. (1994). Eigenproduktionen im Arithmetikunterricht der Primarstufe. Grundsätzliche Überlegungen und Realisierungen in einem Unterrichtsversuch zum multiplikativen Rechnen im zweiten Schuljahr. Wiesbaden:: Deutscher Universitätsverlag.

Shreyar, S., Zolkower, B., \& Pérez (2010). Thinking aloud together: A teacher's semiotic mediation of a whole-class conversation about percents. Educational Studies in Mathematics, 73, 21-53.

Sfard, A. (2007). When the Rules of Discourse Change, but Nobody Tells You: Making Sense of Mathematics Learning From a Commognitive Standpoint. The Journal of the learning sciences, 16(4), $567-615$.

Sfard, A. (2008). Thinking as Communicating: Human Development, the Growth of Discourses, and Mathematizing. Cambridge: Cambridge University Press.

Sfard, A. (2015). Learning, Commognition and Mathematics. In D. Scott \& E. Hargreaves (Eds.), The Sage Handbook of Learning (pp. 129-138). London: Sage.

Shield, M., \& Galbraith, P. (1998). The analysis of student expository writing in mathematics. Educational Studies in Mathematics, 36(1), 29-52.

Strauss, A.L., \& Corbin, J. (1998). Basics of qualitative research. Techniques and procedures for developing grounded theory. Thousand Oaks, London, New Delhi: Sage Publications, Inc.

Vygotsky, L.S. (1978). Mind in Society: The Development of Higher Psychological Processes. Cambridge: Havard University, MA.

Vygotsky, L. S. (1986). Thought and Language. Cambridge, MA: MIT Press. A. Kozulin, Trans. and Ed.

Vygotsky, L.S. (2002). Denken und Sprechen (trans.: J. Lompscher \& G. Rückriem). Weinheim/Basel: Beltz Verlag.

Wille, A. M. (2008). Aspects of the concept of a variable in imaginary dialogues written by students. In O. Figueras, J. Cortina, S. Alatorre, T. Rojano \& A. Sepúlveda (Eds.), Proceedings of the 32nd Conference of the International Group for the Psychology of Mathematics Education (PME32) (vol. 4, pp. 417-424). Cinvestav-UMSNH, Mexico: PME.

Wille, A. M. (2009a). Selbst erdachte Dialoge. mathematik lehren, (156), 22-26.

Wille, A. M. (2009b). Von Schülerinnen und Schülern erdachte Dialoge im Kontext der Zahlbereichserweiterungen in Klasse 5. Beiträge zum Mathematikunterricht, 2009, 921-924.

Wille, A. M. (2010). Steps towards a structural conception of the notion of variable. In V. Durand-Guerrier, S. Soury-Lavergne \& F. Arzarello (Eds.), Proceedings of CERME 6, January 28th-February 1st 2009 Lyon, France. (pp. 659-668). France: INRP. http://www.inrp.fr/editions/cerme6.

Wille, A. M. (2011). Activation of inner mathematical discourses of students about fractions with the help of imaginary dialogues: a case study. In B. Ubuz (Ed.), Proceedings of the 35th Conference of the International Group for the Psychology of Mathematics Education (PME35) (vol. 4, pp. 337-344). Ankara, Turkey: PME.

Wille, A. M. (2013). Mathematik beim Schreiben denken - Auseinandersetzungen mit Mathematik in Form von selbst erdachten Dialogen. In M. Rathgeb, M. Helmerich, R. Krömer, K. Lengnink \& G. Nickel (Eds.), Mathematik im Prozess, Philosophische, Historische und Didaktische Perspektiven (pp. 239-254). Wiesbaden: Springer.

Wille, A.M. (2016). "Die Analysis ist also etwas Unerreichbares" - Wie sich Studierende zentralen Begriffen der elementaren Analysis nähern. To appear in Beiträge zum Mathematikunterricht 2016. Münster: WTM-Verlag.

Wille, A. M., \& Boquet, M. (2009). Imaginary dialogues written by low-achieving students about origami: a case study. In M. Tzekaki, M. Kaldrimidou \& C. Sakonidis (Eds.), Proceedings of the 33rd Conference of the International Group for the Psychology of Mathematics Education (PME33) (vol. 5, pp. 337-344). Thessaloniki, Greece: PME. 